\title{
Outlining a Model of an Intelligent Decision Support System Based on Multi Agents
}

\author{
Nezha Benmoussa \\ Signals, Distributed Systems and \\ Artificial Intelligence Laboratory \\ (SSDIA) \\ ENSET, University Hassan II \\ Mohammedia, Morocco
}

\author{
Meryem Fakhouri Amr \\ Signals, Distributed Systems and \\ Artificial Intelligence Laboratory \\ (SSDIA) \\ ENSET, University Hassan II \\ Mohammedia, Morocco
}

\author{
Souad Ahriz \\ Signals, Distributed Systems and \\ Artificial Intelligence Laboratory \\ (SSDIA) \\ ENSET, University Hassan II \\ Mohammedia, Morocco
}

\author{
Khalifa Mansouri \\ Signals, Distributed Systems and Artificial Intelligence \\ Laboratory (SSDIA) \\ ENSET, University Hassan II \\ Mohammedia, Morocco
}

\author{
Elhossein Illoussamen \\ Signals, Distributed Systems and Artificial Intelligence \\ Laboratory (SSDIA) \\ ENSET, University Hassan II \\ Mohammedia, Morocco
}

\begin{abstract}
Performance optimization has become a necessity for the survival of enterprises as emerging technologies continue to impact them. To achieve this goal, decision making, a complex process which depends on big data and human issues, must be effective. As enterprises are being subjected to a multi-faceted pressure, they must ensure the optimization of their performance. This article investigates an intelligent decision support system (IDSS) based on multi agent systems (MAS). Our contribution consists in developing an intelligent model with an IDSS MAS approach that can detect and evaluate changes in both the external environment and the enterprise itself. This model is an adequate management tool for optimal and sustainable performance and offers real-time analytical, prospecting and optimization methods.
\end{abstract} IDSS

Keywords-decision making; performance; value creation; MAS;

\section{INTRODUCTION}

Strategic decisions are the result of a complex process and they often refer to the complexity degree of decision-making issues and the environment in which an enterprise/company operates. For authors in [1], it refers to important decisions, in terms of actions taken to resources committed and jurisprudence. According to [2], there are decisions that especially focus on external environment. A decision is not always easy to take and in order to overcome the unexpected risks to manage, leaders seek to always be more effective when it comes to decision support tools usage. According to [3] decision support is considered as a science based on three assumptions: (a) postulate of reality: to have information and especially knowledge, (b) postulate of the decision-makers: act as a power actor according to the objectives set and the resources available and (c) postulate of the optimum i.e. optimize the decision. This basis principle is conditioned, in general, by various factors including environment changes and technological growth. Nowadays with the digital transformation in the field of information systems, no enterprise can escape the use of new technologies that greatly facilitate data processing and sharing. In fact, more and more specialized software offers the possibility of carefully analyzing the data for a reliable result that will allow a quick and efficient decision-making. Virtualization has become, therefore, an important tool enabling companies to be more responsive thanks to the different production and management applications. Thus, artificial intelligence has no privacy for companies because it has integrated most of their functions and has become a means of data sharing, performance measurement and optimal decision-making thanks to the combination of human and artificial intelligence. Indeed, in a highly competitive environment, enterprises seek to meet market demands and are constantly in need of solutions that enable them to be effectively reactive to the environment for greater competitiveness. The distributed decision process is an effective means of sharing, prevention and decision-making.

The proposed model, an intelligent decision support system (IDSS) based on Multi Agent Systems (MAS), is part of computer intelligence and therefore business intelligence (BI). It would enable the enterprise to collect, model and report data to provide decision support for driving and optimizing decision-making.

\section{A. Performance}

According to [4], performance is an encrypted result from the perspective of classification (in relation to oneself, improve performance / or compared to others). Long-term performance has been reduced to its financial dimension. Thus, a successful company is one that must reach the desired, by the shareholders, profitability and/or generate a certain level of 
profit, or hold market share that preserves its sustainability [5]. Performance is the ability of an enterprise to exploit its environment in the acquisition of scarce resources essential to its operation [6]. Some authors equate performance with efficiency, ability or competitiveness, productivity, success and excellence [7]. The traditional definition of performance derives through a composition of efficiency and effectiveness [8]. According to [9], effectiveness is evaluated in relation with specific objectives of the company and the degree of result achievement and is likely to be attached to the notion of mission as it is a measurable result to be achieved. Efficiency can be defined as the sum of outputs achieved (results achieved) by inputs units (means) engaged. The concept of performance can be defined in different ways. It means completion and it is also treated as competitiveness, effectiveness, efficiency and productivity. Commonly, the four other meanings are:

- The capacity of the potential of the natural or legal person's "skills and strategy".

- The processes used to achieve the desired results, "tools".

- The results of actions measured against an endogenous or exogenous reference.

- The quantitative and qualitative indicators and success defined objectives for example satisfaction, action plan, cost and time.

Moreover, the performance's dimensions define four complementary levels related to each other which a manager can follow to set a good strategy: financial results, customer satisfaction, efficient internal processes and organizational system. With the help of an expert system, this performance can be comprehensive and will ensure effective management in all situations. We can deduce that performance occupies a very important place in enterprises. It is their main ambition and also the key business process. In [10], performance is the ability to achieve a minimum of meeting the expectations of strategic customers and optimal benefit. These are the three types of performance:

- Organizational: A structure seeking to minimize the transactions.

- Social: Social effects of structure's activity are such that have ways of preventing and managing conflicts and they motivate and involve more staff.

- Economic or financial: Structure achieves profitability.

The challenge for enterprises is to improve and optimize their performance through effective decisions. Thus, the implementation of a management decision system is a value creation lever that allows them to achieve effectiveness and efficiency in the actions.

\section{B. The Intelligent DSS}

Called "System Computerized Decision Support" (DSS: Decision Support System) or "Interactive System Decision Support" or "System of Intelligent Decision Support", IDSS is an integrated computer system, designed especially for decision-making and especially aimed at company leaders.
IDSS is one of the management information system elements. It differs from the information system, since its main function is to provide not only information, but the analytical tools for decision making. It consists of programs, one or more databases, internal or external, and a knowledge database. It works with a language and a modeling program that enables leaders to study different assumptions for planning and evaluating the consequences. One of the first introductions of management decision systems (MDS) or DSS was in [11]. These systems provide decision makers with an aid in the decision-making even in complex and unstructured situations. They became effective at the end of the $70 \mathrm{~s}$ when the various operational decision support tools have emerged and took the name of Interactive DSS. The intelligent DSS is a computer system to help decision makers that deal with semi-structured problems [12-15]. According to [16], a DSS is an automated information system, interactive, flexible, adaptable and specifically developed to help solve an unstructured decision problem and improve decision making. Powered by potentially all financial applications, commercial and administrative, of the enterprise, IDSS is a tool of observation and description that will enable managers to monitor activity, detect and alert management reshape the strategy to the needs of the company and its environment. However, it provides no explanation or commentary but using dashboards, reporting, and a MAS approach, the data is easily interpreted, processed and shared.

\section{Multi Agent Systems (MAS)}

Multi agent systems have been the subject of some studies and have been treated differently [17-19]. The concept of fuzzy logic was introduced in [20], not only as a control methodology but also as a way to process data based on authorizing the use of membership in a small group instead of making use of membership in a cluster group. In the field of artificial intelligence, MAS reduce the complexity of solving a problem by dividing the necessary knowledge into subsets, combining an independent intelligent agent to each of these subsets and coordinating the activity of these agents [21]. A multi agent system is a system consisting of agents. These agents each in its own turn, have internal interactions and are also related to the external environment. An agent is an autonomous computer system or program capable of carrying out independent actions. [20]. Agents need to cooperate with each other, to have harmony amongst themselves and to carry out interactive conversation in order to have successful internal communication. A multi agent system or distributed artificial intelligence is, therefore, a set of IT processes composed of several agents sharing resources and communicating with each other [22]. This communication is provided by different protocols and message types. Thus, the mechanisms of the agents' decisions are related to perceptions, representations and actions by all agents that cooperate to achieve a common task or a negotiation between those whose interests are different [23]. In [24], an agent is a "computational entity" as a computer program or a robot, which can be seen as perceiving and acting independently on its environment. This is an automatic autonomy since its behavior depends on the program and experience. Development and implementation of DSS continues to hold great promise for improving decision maker's effectiveness [25]. The combination of these two processes 
DSS and MAS, allowed us to think about the development of an IDSS MAS model that will be a crucial contribution in the exchange and decision making.

\section{THE INTELLIGENT DSS MAS MODEL}

An enterprise has several levels of competitiveness but to be effectively controlled, strategic dashboards are essential. It is in this context that our IDSS MAS model takes place to facilitate decision making and specially to allow optimal decision. Indeed, to avoid long consultations and possible constraints of updating, as well as to enable the management of contingencies, BI systems provide powerful analytical methods and exploration in real time that help in decision making. Our IDSS model based on MAS is a part of the BI. It aims to provide a convenient, easy-to-use reference tool for minimizing information retrieval tasks by presenting results via dashboards and reports. Communication is permanently established between the principal agent and the solver-agent who collects and transmits the data according to the allocated objectives. IDSS MAS supports decision-makers by helping them to easily identify decision variables and to analyze several alternatives to optimize it. It is an expert system that makes possible to respond to a specific need based on provided human knowledge and that is part of its program. Indeed, its main function is to target the relevant facts relating to a given situation (innovation, improvement or problem solving etc.) to present justified recommendations.

\section{A. The Operation of theI DSS MAS Model}

The IDSS MAS model facilitates communication and decision-making via agents which are connected to the web and which have strong relationships with the internal and external environment of the company. The needs are expressed to these multi agents which are programmed by TST (Technical, Services and Training) functions. Thus, the technical agent (TA) will collect all new technology on the market. The service agent (SA) will collect data on the prospects of services offered nationally and internationally. The training agent (TA) will indicate the key elements of the training to be taken into consideration. These data are communicated in real time to the main key performance indicator (KPI) agent which transforms them into objectives and indicators, thus facilitating decisionmaking. The process of operation of the IDSS MAS model is schematized in Figure 1. These multi agents are coupled to the environment, linked to KPIs and operate independently of each other. All TST indicators generated by the KPI agent will be used as the basis for the IDSS MAS model to prepare the knowledge that will feed the user interface with balanced reports and dashboards. The model is presented in Figure 2.

The peculiarity of the IDSS MAS model is the use of MAS represented by different agents. Each agent plays a definite role and has specific features. This model is capable of aggregating internal and external data from multiple and different databases (DB1, DB2, DB3, etc.) and turn them into knowledge for taking a rapid and effective decision. In a first phase, it collects the data sources that can be in different formats and are heterogeneous. This data is then manipulated in a second phase called integration before being stored. They are to be extracted from data sources, transformed and loaded into the data warehouse (DWH) using an ETL (Extract, Transform and Load) agent. The third phase is to store them in the warehouse by using the DWH agent. This multidimensional data structure optimizes response times by using the OLAP (online analytical processing) cube agent. Finally, the results are presented by the restitution agent that uses several data presentation tools for example reporting, query and data mining. The details and actions of each agent are listed in Table I.

\section{TABLE I. IDSS MAS AGENTS' ACTIONS}

\begin{tabular}{|l|l|} 
It is at this level that the first software layer of the decision-making \\
environment namely ETL (extract, transform, load) appears. ETL \\
extraction agent offers functions of data from different systems (internal \\
or external), processing of data (homogenizing, filtering, calculation) \\
and their change in an ODS (Oracle Data Store) or directly through \\
DWH. It guarantees the outsourcing of design load and better \\
availability of sources. ETL agent transforms data, while it uses a \\
dedicated proprietary engine that is responsible for processing. This \\
ensures the best performance and scalability over time.
\end{tabular}

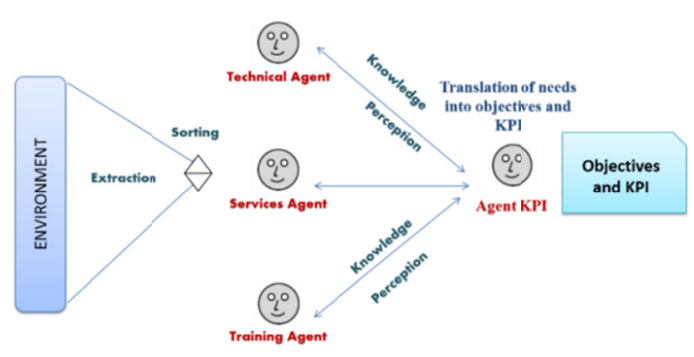

Fig. 1. Operating prosses of IDSS MAS

The model that we propose is being developed and tested to validate its feasibility. We will develop the model DSS MAS with Oracle technology. For the first phase of extraction and loading of data, we appeal to ODI (Oracle Data Integrator), which is part of the Oracle suite. It allows the ensuring of the ELT (extract-load-transform) process for the extraction, 
loading and transformation of data. In the second phase, we use OBIEE (Oracle business intelligence enterprise edition) for the generation of the OLAP cubes and data marts. Finally, we use the reporting for the dashboards restitution. This draft algorithm clarifies the example of data collection and their transformation into KPIs.

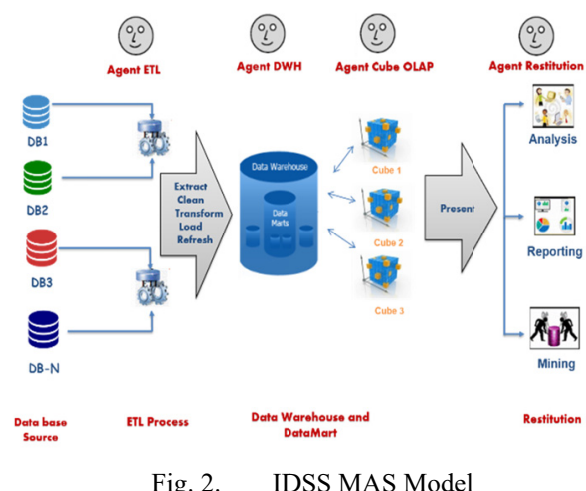

Fig. 2. IDSS MAS Model

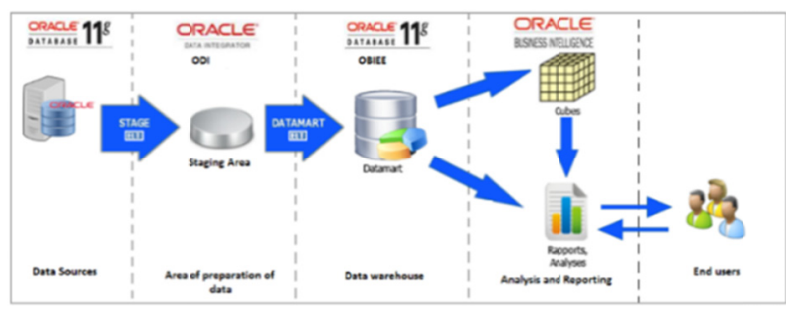

Fig. 3. Technical solution of IDSS MAS

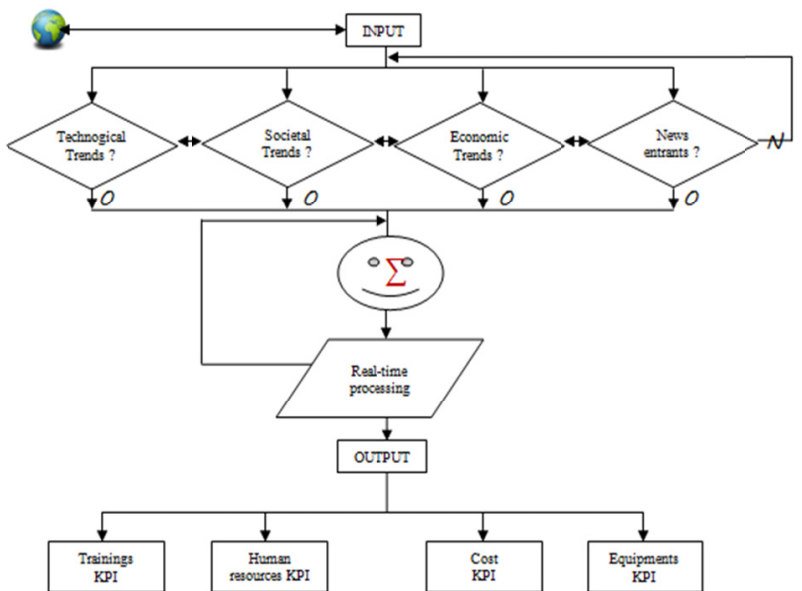

Fig. 4. Model IDSS MAS Algorithm

\section{B. The Sequence Diagram of IDSS MAS}

The chronological process of the different interactions of agents constituting the IDSS MAS model is illustrated Figure 5 which details the overview of the software engineer. The diagram in Figure 5 represents the interaction between the different system factors. Agent 1 expresses a need to the main agent that is responsible for the analysis and translation of the company's KPIs. Subsequently these KPIs are transmitted to the DB agent in a SQL query form and will be translated by extraction, loading and transformation of data collected through the execution of these queries by the ETL agent. The agent performs the DWH design task that will be the basis of development of dashboards and reports.

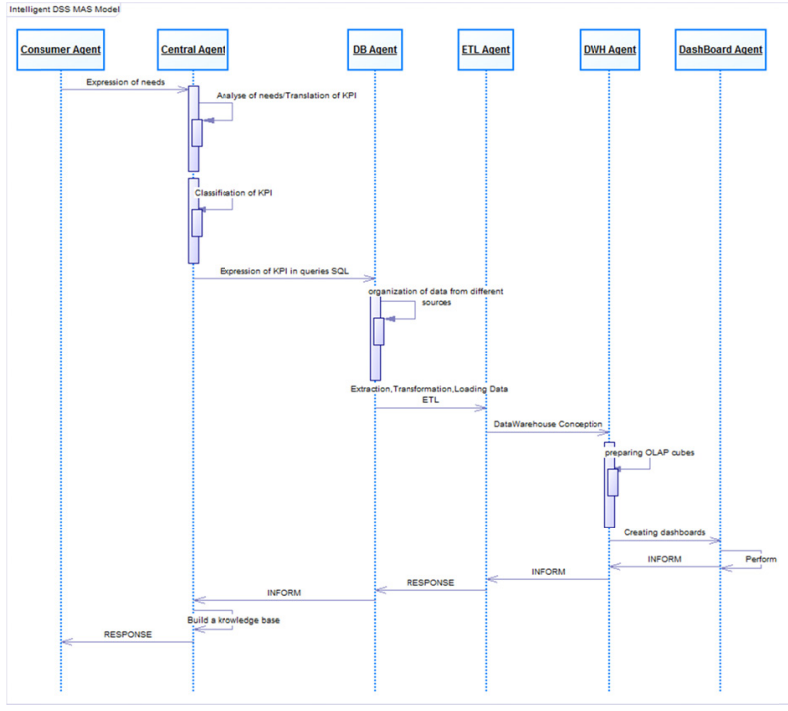

Fig. 5. Sequence diagram of IDSS MAS

\section{Methodology}

We consider expressed needs that require data collection by agents and translators connected to the principal agent. The result of these interactions is the KPIs allow the making of effective decisions concerning human resources and material means. These KPIs are passed to the DB agent. The latter requests the ETL agent to translate by extraction, loading and transformation of collected data. Subsequently DWH is a task that will be used as a basis for developing dashboards and reports using the dashboard agent. The latter sends a feedback to the DWH agent who will use this data in his knowledge base before informing the ETL agent which will also use this data to build his learning system. Once the DB agent receives a response from the ETL agent, it informs the central agent summarizing the feedback of the previous agents. In turn, the central agent will record this data in his knowledge base which will be exploited by his inference engine to determine the appropriate profile of the consumer agent and therefore provide him with an appropriate response to his need. For a clear view of the contribution of the IDSS MAS model, we compare below the DWH and data mining process by highlighting the different characteristics of each.

\section{Disscussion}

IT solutions have high potential for process optimization in reengineering or restructuring strategies through a continuous improvement approach. Each process has advantages and limits. These are still the subject of research that leads either to process development or its substitution. If the DWH is a datarich repository and data mining makes knowledge available to users, our IDSS SMA model will not only enable data collection and processing, but also the preparation of data and 
the selection of adequate knowledge for effective decisionmaking. In addition, it can also offer various decisions that can help the manager. The following comparative study shows the characteristics of DWH, Data Mining and our IDSS MAS model whose functionalities are varied and intelligent compared to the first two processes, especially in terms of interactions of Multi Agents in real time and assistance to improve the decision-making. Table II presents a comparison between the two main systems used for decision making and our IDSS MAS model. Through this comparative study, we can conclude that the proposed IDSS MAS model has several advantages over DWH and Data Mining, especially the coupling between the decision model and the MAS which allows task division and multiple targeted interactions offering reliable data and subsequently accurate indicators improving the decision-making system.

TABLE II. DATA WAREHOUSE, DATA MINING AND IDSS MAS MODEL COMPARISON

\begin{tabular}{|c|c|c|c|}
\hline Criteria & $\begin{array}{c}\text { Data } \\
\text { Warehouse }\end{array}$ & $\begin{array}{c}\text { Data } \\
\text { Mining }\end{array}$ & $\begin{array}{l}\text { IDSS } \\
\text { MASS }\end{array}$ \\
\hline Problem Definition & $\mathrm{X}$ & & $\mathrm{X}$ \\
\hline Data gathering & $\mathrm{X}$ & & $\mathrm{X}$ \\
\hline $\begin{array}{c}\text { Selection of the analysis } \\
\text { model }\end{array}$ & $\mathrm{X}$ & & \\
\hline Study results & $\mathrm{X}$ & & $\mathrm{X}$ \\
\hline $\begin{array}{c}\text { Formalization and } \\
\text { distribution }\end{array}$ & $\mathrm{X}$ & & $\mathrm{X}$ \\
\hline Identifying needs & & $\mathrm{X}$ & $\mathrm{X}$ \\
\hline Data modeling & & $\mathrm{X}$ & $\mathrm{X}$ \\
\hline Data deployment & $\mathrm{X}$ & $\mathrm{X}$ & $\mathrm{X}$ \\
\hline Expression of needs by agent & & & $\mathrm{X}$ \\
\hline $\begin{array}{c}\text { Translation requirements by } \\
\text { the central agent KPI }\end{array}$ & & & $\mathrm{X}$ \\
\hline $\begin{array}{c}\text { Viewing reports and } \\
\text { dashboard in real time }\end{array}$ & & & $\mathrm{X}$ \\
\hline $\begin{array}{c}\text { Receiving and processing } \\
\text { needs by each agent }\end{array}$ & & & $X$ \\
\hline $\begin{array}{c}\text { Specific role and } \\
\text { independent task by agent }\end{array}$ & & & $X$ \\
\hline $\begin{array}{l}\text { Help to improve the decision- } \\
\text { making process }\end{array}$ & & & $\mathrm{X}$ \\
\hline $\begin{array}{c}\text { Possibility of adding a } \\
\text { decision agent }\end{array}$ & & & $\mathrm{X}$ \\
\hline
\end{tabular}

\section{CONCLUSION}

In this article, we presented different performance concepts and the proposed IDSS model that has a significant impact on the management of enterprises in general and on decisionmaking in particular. Our study also provided a comparison between different systems such as data warehouse, data mining and our IDSS MAS model to emphasize its advantages that are data analysis, sharing of real-time knowledge and above decision support. Indeed, the general interest of this analysis is to guide decision-makers towards intelligent tools of decision support in a complex and evolving system for more efficiency and competitiveness. We deduce, therefore, that artificial intelligence can drive and optimize the performance of enterprises through different systems with human reflections and intelligences. Indeed, the integration and popularization of the IDSS MAS model will certainly contribute to the efficiency of the decision-making process of enterprises for optimal, balanced and sustainable performance. It will avoid long consultations, possible update constraints and will allow the management of the unforeseen by the realization of an in-depth diagnosis, real time sharing of knowledge and the performance evaluation for future optimization. Finally, our cross readings have shown that in the educational field, despite the implementation of different platforms, universities do not have yet artificial intelligence at the decision-making level. For this reason our perspective is to implement the IDSS MAS model in order to validate it and integrate it into academic institutions for real-time data sharing between stakeholders and effective decision-making through precise indicators concerning both the administrative component, that requires flexibility and rapid implementation, and the offered student training and skills that meet the needs of the market.

\section{REFERENCES}

[1] H. Mintzberg, D. Raisinghani, A. Theoret, "The structure of "Unstructured" decision processes", Administrative Science Quarterly,Vol. 21, No. 2, pp. 246-275, 1976

[2] H. I. Anssof, Corporate Strategy, McGraw Hill, New York, 1965

[3] B. Roy, D. Bouyssou, "Aide multicritère à la décision- Méthodes et cas", Economica, Paris, 1993 (in French)

[4] T. Quach, K. Oanh, "Une perspective de recherche sur la performance dans l'organisation", 23e Colloque annuel du Conseil Canadien des PME et de l'entrepreneuriat, Trois-Rivières, 2006 (in Frenc)

[5] I. Missaoui, "Valeur et performance des systèmes d'information", Cahier de charge $\mathrm{N}^{\circ} 5$, CIGREF - Université Paris-Sud 11, Paris, 2009 (in French)

[6] M. Bouamama, "Nouveaux défis du système de mesure de la performance : cas des tableaux de bord", Gestion et management. Université de Bordeaux, 2015 (in French)

[7] F. Nwamen, "Impact des technologies de l'information et de la communication sur la performance commerciale des entreprises", Revue des sciences de gestion, No. 218, pp. 111-126, 2006(in French)

[8] P. Amans, S. Rascol-Boutard, "La performance entre construit social et indicateur simplifié", Finance Contrôle et Stratégie, Vol. 11, No. 3, pp. 45-63, 2008 (in French)

[9] M. Gervais, Contrôle de gestion, Economica, 2005 (in French)

[10] A. Bourguignon, "Peut-on définir la performance?", Revue Française de Comptabilité, No. 269, pp. 61-66, 1995 (in French)

[11] M. S. Scott-Morton, Management Decision System, 1971

[12] P. G. W. Keen, M. Scott-Morton, "Decision Support Systems : an oragnizational perspective", AddisonWesley Publighing, 1978

[13] R. H. Spargue , E Carlson, Building Effective Support Systems, Prentice-Hall, Inc, Englewood Cliffs, 1982

[14] P. N. Finlay, Introducing Decision Support Systems, NCC Blackwell, 19889

[15] A. R. Probst, "Les Systèmes d'Aide à la Décision : rôle, structure et évolution", Gestion-Revue In ternationale de Gestion, Vol. 9, No. 4, pp. 13-19, 1984

[16] E. Turban, Decision Support and Expert Systems: Managerial perspectives, Macmillan Library Reference, 1990

[17] S. Shamshirband, N. Badrul Anuar, M. L. Mat Kiah, A. Patel, “An appraisal and design of a multi-agent system based cooperative wireless intrusion detection computational intelligence technique", Engineering Applications of Artificial Intelligence, Vol. 26, No. 9, pp. 2105-2127, 2013

[18] S. Shamshirband, A. Patel, N. Badrul Anuar, M. L. Mat Kiah, A. Abraham, "Cooperative game theoretic approach using fuzzy Q-learning for detecting and preventing intrusions in wireless sensor networks", Engineering Applications of Artificial Intelligence, Vol. 32. pages 228241,2014

[19] A. Jahangirzadeh, S. Shamshirband, S. Aghabozorgi, S. Akib, H. Basser, N. Badrul Anuar, M. L. Mat Kiah, "A cooperative expert based support 
vector regression (Co-ESVR) system to determine collar dimensions around bridge pier", Neurocomputing, Vol. 140, pp. 172-184, 2014

[20] S. Shamshirband, S. Kalantari, Z. Bakhshandeh, "Designing a smart multi-agent system based on fuzzy logic to improve the gas consumption pattern", Scientific Research and Essays, Vol. 5, No. 6, pp. 592-605, 2010

[21] J. Ferber, Les Systèmes Multi Agents vers une Intelligence Collective, InterEditions, Paris, 1995 (in French)

[22] B. Nachet, A. Adla, "An agent-based distributed collaborative decision support system", Intelligent Decision Technologies - Various forms of intelligence, Vol. 8, No. 1, pp. 15-34, 2014

[23] N. Bakhta, Modèle multi-agents pour la conception d'un SIAD collective, PhD Thesis, Université d'Oran, 2014, (in French)

[24] G. Weiss, Multiagent Systems, MIT Press, 2013

[25] S. H. Chan, Q. Song, S. Sarker, R. David Plumleed, "Decision support system (DSS) use and decision performance: DSS motivation and its antecedents", Information \& Management, Vol. 54, No. 7, pp. 934-947, 2017 